\title{
Vulnerabilities and resilience in Danish housing stock: $A$ comparative study of architectural answers to climate change in Danish housing in relation to other oceanic climates
}

\author{
Mikkel Poulsen Rydborg ${ }^{1, *}$, Michael Lauring ${ }^{1}$, and Camilla Brunsgaard ${ }^{1}$ \\ ${ }^{1}$ Aalborg University, Dept. of Architecture, Design and Media Technology, Aalborg, Denmark
}

\begin{abstract}
Climate change will affect the same climate zones relatively similarly. When considering how to design residential architecture for future climates it is therefore relevant to understand how residential architecture can adapt within the specific climate zone.

Denmark is placed within the oceanic climate zone and shares many of the same problems that countries in similar climates do. However, the architectural responses have developed radically different. Denmark has been building heating efficient housing for the last decade, which have lately caused increased overheating problems and surging energy demands for cooling.

This paper compares the architecture of different oceanic zones with Danish architecture. The strategies for adapting to climate change represents a broad variety.

Western European tradition has itself created varied methods for coping with the climatic struggles their societies meet. Danish architecture has for centuries been focused on heavy robust constructions that would withstand the large amount of precipitation and wind that is predominant in the country. In Holland flood danger has been a constant threat to society, which has led both to defensive and reactive measures in the form of dykes and amphibious housing. On the other side of the globe, New Zealand's traditional architecture has adapted to similar problems but with a much lighter construction, leading to architecture that is resilient to lateral forces like wind and earthquakes. While lacking the thermal properties of northern European houses the New Zealand homes show a remarkable flexibility and mobility through simple timber-frame constructions.

The vulnerabilities in the Danish building stock is due to an unwillingness to invest in adaptive measures. It might be necessary to integrate a flexible building style to future sustainable housing and build up a different expectation for how a house is used. In the face of climate change, architecture need to be adapted to the problems apparent on the building site and draw on experiences from other cultures that might have faced similar problems in the past. Danish architects might likewise use the non-rocky ground for water retention through planting and landscaping strategies in relation to architecture.
\end{abstract}

\section{Introduction:}

Climate change is the defining issue of our time. The Intergovernmental Panel on Climate Change (IPCC) has just recently issued its latest report giving humanity only a small window to escape the most devastating effects of climate change [1],[2].

This paper focus on three case countries, Denmark, Holland and New Zealand. Each represent different versions of oceanic climate zones as defined by the Köppen climate classification [3]. Investigations into each country's bioclimatic approach in the typical house are made; what vulnerabilities each country face concerning climate change in the housing stock and what potentials for climate change adaptation exist in the residential architecture. The paper concludes with a discussion of adaptation in Danish residential architecture related to the other cases.

\subsection{Background}

The studies presented in this paper are based on the ideas of bioclimatic and natural resilience in architecture, where resilience and adaptation to climate change can be improved through the integration of landscape and natural elements as part of the architectural design.
Therefore, understanding vulnerabilities and the adaptive capacity in different countries within the same climate zone can be valuable in determining how the residential architecture in oceanic climates should meet the challenge of climate change. Residential architecture is often economically constrained [4], and adaptive measures should

Economy is a key issue that needs to be addressed in the realm of climate change adaptation. Houses rely on the residents for maintenance and refurbishment, which leads to just the most necessary and affordable undertakings in the residences, unless the inhabitants do refurbishment and developments actively on their own [4],[5]. Also social housing organizations are greatly affected by the economy of their inhabitants [6].

Therefore, the discussion presented in this paper will be from a position of improving residential architecture within the realm of economic reason for the inhabitants.

\section{Methods}

\subsection{Literature Studies}

The results presented in this paper are based on an extensive literature study, both on the subject of climate change adaptation of architecture, and on regional

* Corresponding author: mpou@create.aau.dk 
architecture in the case countries. The litterary subject is on both traditional and modern housing as well as climate change adaptation strategies that are prevalent in each country [7].

\subsection{Comparative Studies}

To understand the different architectural traditions, certain cases are used as examples of the current housing situation in the countries. The studies will look at modern standard residences in different countries and compare their vulnerabilities and adaptive potentials to one another. The conclusion focus on comparisons with the Danish housing stock rather than between all three cases. Condensed generalizations will have to occur to encompass the scale of the project [7].

\section{Bioclimatic Architecture in Oceanic climates}

Relatively small swings in temperatures during the year, high air humidity, a large amount of precipitation especially in winter and strong oceanic winds that can reach high wind speeds but only rarely catastrophic levels are what defines the oceanic climate zones.

The proximity to the ocean temperate the climate and dampens the annual variance in ambient temperature. Only the colder countries within the zone have historically required large amounts of insulation to withstand low winter temperatures. Shedding precipitation has always been driver in the bioclimatic form finding of the oceanic house; even in the relatively drier regions of New Zealand, compared to the other case countries, pitched roofs with overhangs are standard elements of the architecture.

The precipitation in the environments lead to considerations on how the architecture meet the ground and the curvature in the landscape. Failure to recognize these considerations will lead to failure in the structural and humane comfort properties in the architecture [1],[3].

\subsection{Denmark}

The Danish landscape has no bedrock and is a low land archipelago around the main peninsula of Jutland. In Denmark, important bioclimatic influences on building design are wind, precipitation, temperature and light. Since the country is on the highest latitude of the cases, the temperatures tends to be lower and the sunlight hours in winter are few. Therefore, a major focus in Danish residential architecture has been allowing daylight in the interior while shedding precipitation and wind with the building envelope.

Traditional Danish houses have been oriented towards the sun and away from wind. They have a pitched roof to shed rain and snow, in some cases with overhangs to protect the envelope. Though in the most wind stricken regions, like the west coast of Jutland, the overhangs should not catch the uplift forces and are therefore significantly smaller [8],[9].
Residences are mainly heavy constructions. Older houses are masonry while newer ones tend towards concrete constructions. However, wooden houses have started to gain some traction with the rising sustainable requirements and awareness in the building sector, since the embedded energy is lower in timber constructions, although this is not expressed in the Danish building code yet [10].

The traditional heavy construction originates with the deforestation of Denmark during the middle ages, when earth dug poles were outlawed by royal decree and replaced by stone foundation. Timber houses were over centuries replaced by half-timber and finally brick stone buildings. The deforestation of the country allowed for increased wind speeds and therefore wind shelter gained importance in traditional design [11],[12].

The contemporary Danish house has lost some of its bioclimatic features due to a larger demand for quickly built housing of prefabricated elements and efficient exploitation of the interior space. The pitched roofs are in contemporary houses often replaced with lower, almost flat, roofs, which sheds rain but gathers snow. Orientation to wind has become less important due to the tighter envelope, although the hurricane storms of winter, which have started to take hold in the last 20 years, tends to cause damage in the building mass.

\subsection{Holland}

Holland has a low altitude coastal landscape similar to Denmark. It is flat and without bedrock in most of the country, due to the artificial reclamation from the sea by damming in areas and pumping out water. Therefore, a large part of the country is below sea level. The residence in Holland is designed for the flat, windy and humid environment.

The residences in cities are often tall and narrow row and infill houses to account for the lack of space. The height of the building can provide the inhabitants safety from floods. The ground floors are raised, with light constructions on the ground floor and heavier on the higher floors, making them essentially pole houses. Most of the traditional residences are timber frame constructions with heavy cladding, while modern and contemporary residences are heavy constructions of either masonry or concrete [13].

The roofs of traditional houses are pitched to shed precipitation. The traditional houses tend to have a very high roof pitch compared to Danish houses. The gables in the terraced housing are in some case turned towards the streets, exemplified by the "Halsgevel" in Amsterdam's houses, which could indicate less concern for snow. But most modern terraced houses are connected to one another at the gables.[13],[14]

\subsection{New Zealand}

New Zealand has a wealth of varied landscapes and biomes represented on the two main islands; the country is approximately the size of England but with only 4.5 
million inhabitants [15]. The Common New Zealand house is of a light timber frame construction dimensioned to withstand the horizontal forces of wind and earthquakes. The construction is "light but muscular". Pitched metal roofs sheds and withstands the cyclonic downpours. The light construction houses are quick to build, modifiable and moveable.

Older houses have only a light layer of insulation, if any, and lack a centralized heating system. Therefore, the buildings are very susceptible to the changes in ambient temperature and have a lack of thermal mass; the interior temperatures will only differ slight from the exterior without a substantial heating source. On the colder South Island, this is a particular problem. New building standards does demand better insulation and tighter envelopes, although far from the standards of the European cases [16],[17].

\section{Vulnerabilities to Climate Change}

The vulnerabilities of housing design to climate change in oceanic climates are largely dependent on the individual countries' cultural background in residential developments, which in turn shape building policies. There are also individual landscape formations and natural events to take into consideration.

\subsection{Denmark}

The residential developments in Denmark are vulnerable to changes connected to sea level rise and increased precipitation.

Most of the adaptations in Denmark is storm flood and sea rise management [18]. The natural coastal erosion along the Danish coasts is increasing due to climate change, which has led to the destruction of properties along the western coast.

Flooding is an increasing problem since many cities in Denmark are low lying or built near coastal erosion areas. Fjords and sounds perforate a large part of the Danish coast and can be a source of flooding further inland; some of them can flood excessively due to storms, tides and changes in flow. Cities like Nakskov on the island Lolland are built below sea level on reclaimed land, which makes it further vulnerable to flooding [19].

The expanding areas of impermeable surfaces in cities and suburbs have likewise increased the possibility for flooding from both storms and cloudbursts [20].

Heavy constructions, that are prevalent in Danish buildings, are ill suited for the changing landscapes and hinders a larger degree of flexibility and mobility in the design. Some houses are resilient to the increasing storms. But the lack of flexibility and mobility results in houses that can be particularly maladapted to climate change related to flooding. The heavy structures of the concrete and brick houses does not correspond well with a mutable landscape, that will start to behave differently as the climate changes[9],[21].
Denmark has until now been in a heating zone, but new regulations require well-insulated envelopes, which have started to make summer overheating a common problem in Danish housing [22]. This problem will become worse with increasing average temperatures. The indoor environment problem can be alleviated through active measures like air conditioning (AC). However, AC will increase the energy consumption of the buildings and therefore CO2 emissions. Since the Danish energy grid still relies largely on non-renewable energy sources emitting greenhouse gas, although with an expanding source of renewables.

\subsection{Holland}

In Holland, the main concern related to climate change is floods, with extreme flood events becoming more frequent due to sea rise. The tall infill housing designs may enable some flood protection for the residents as they can seek shelter on the upper floors. Many older buildings were designed with light constructions on the ground floor that would give way during floods [14]. There are amphibious designs that have started to take hold in the more exposed areas of Dutch developments, but most housing still relies on the large scale flood protections to keep themselves safe [23]. Investigations into Dutch public housing have shown, that while there are some awareness of the climate change issues in the housing sector, the motivation to allocate the resources and economy to adapting the buildings are low [6].

The density of the Dutch cities could also lead to increasing problems with the urban heat island effect. Simulations have shown that most houses will be able to withstand the low-level effects of climate change to the temperature. However, the same studies show that houses will have to use air conditioning if they should adapt to long-term temperature change [24]. This problem could offset the efforts to create a more sustainable building stock [25] with lower energy consumption. Especially when the predicted reliance on air conditioning will worsen the urban heat island.

\subsection{New Zealand}

New Zealand has taken only few initiatives to create and maintain sustainable heating strategies. The lacking focus on energy demand is due to the New Zealand energy coming mostly from renewable sources; traditionally wind and hydro power [26]. Sustainability is in New Zealand rather focused on lowering environmental impact through material use, building footprint and assembly [27].

As described in the previous section the New Zealand house is in most parts of the country already maladapted to the climate. Most housing especially on the South Island will benefit from warmer average temperatures, when considering indoor climate. The houses are vulnerable to humidity and the health issues that follow from poor indoor climates, having one of the highest frequencies of child asthma as a result. New residences need to uphold stricter codes to insure the indoor 
environment, but most of the existing housing stock will need renovation or replacement to withstand the increasing humidity in wintertime [16].

The light timber structures allow high flexibility and mobility and is suitable for horizontal forces like wind and earthquakes. The light timber structure are vulnerable in areas that can become prone to flooding, the structure might not resist floods and return to a usable state afterwards. Therefore, the houses in flood prone areas need to be either elevated or relocated, which is not currently happening [9].

\section{Potential climate change adaptation strategies}

This section describes potential adaptation strategies based on the building culture and vulnerabilities. The local building culture influence the adaptive capacity of regional housing. The case countries have distinct standard design features, which might adapt to climate change on the building scale. Comparing the potential regional adaptation methods could reveal strategies to incorporate broadly in the oceanic climate zones.

\subsection{Denmark}

Contemporary Danish housing has a large amount of integrated technology to minimize energy consumption and avoid discomfort in the inhabitants. The houses are primarily constructed by prefabricated elements. Therefore, Danish residential architecture might have some adaptive capacity in the high-tech system integration, due to the use of active technologies in plenty of the sustainable houses that have been designed both for testing and habitation to meet the strict and increasing energy standards of the Danish building code [22],[28]. The houses that already adapt to changes over seasons and could be resilient, if the systems are designed with a level redundancy.

Danish housing design has in recent years been driven by an increasing regulatory requirement for lower energy consumption, which has guided the housing architecture into designs that can take on a multitude of forms, but which do retain similar features of achieving sustainability. The houses have thick high-insulating envelopes that can be functionally integrated into the architecture if the surfaces around openings are incorporated into the spatial composition. Otherwise, the thick envelopes can function partly as shading, which will become further relevant in future Danish architectural design as the passive solar contribution to the energy frame will have a negative impact on cooling demand in a warming climate.

The technologically dependent designs could require additional passive or user driven design features, otherwise it may become maladapted over time. Reflective surfaces, adaptive arrangements of functions and the like could help the buildings in times of disruption. Arranging the functionalities in house in such a way that inhabitants in the event of heatwaves will be able to actively cool a small part of the house to avoid discomfort while minimizing the energy used by the cooling. The residents will take up habitation in a few rooms, most efficiently basements, which they will exclusively inhabit for the duration of the heatwave [29],[30]. The envelopes and heavy construction, with plenty of thermal mass, might help the Danish housing stock resisting temperature change if the building use changes to primarily cool the building rather than heat it. The Danish-building sector have been regulated towards lower energy demand and might be more open for regulations that can increase resilience to climate change compared to especially New Zealand, where regulations in the building sector are still rather new and lax compared to the Denmark.

\subsection{Holland}

Dutch residential architecture live with water. There are several cases of amphibious buildings expanding both the livable area and providing resilience to flooding at the same time. The developments of amphibious houses on larger scales or as a standard housing types, do have many impracticalities especially with regard to electrical installations and plumbing, how these should connect and reconnect [9][23],[31].

Simulations show that most Dutch residences will not be influenced much by increasing temperatures, but might need sustainable passive solutions in the long term if the housing is supposed to keep a low energy demand, again reflective surfaces, intelligent shading and layout of functions based on indoor environment could. Sustainable housing in Holland is still going to face similar problems like other places in the world with overheating and large increases in energy demand, because of a singular focus on energy reductions due to heating demand, that may leave the buildings vulnerable to the rising temperature [24].

Dutch housing is more attuned to the threat of flooding; a lot is done in large scale planning, and plenty housing plans actively work with water management as a part of the scheme [32]. The largest threat to the Dutch housing is rather the lack of economy and initiative to change [6],[33]. This is a frequent problem in climate change adaptation of housing because of the vague and inevitable nature of the problems [4],[5].

\subsection{New Zealand}

The New Zealand building culture lends itself to a reactive and sometimes naturally embedded strategy in response to climate change. The buildings' affinity to the existing natural disasters provide a basic adaptation potential. The ability for the buildings to be moved in response to sea rise and precipitation floods provide resilience in those homes that are of light construction; the movable housing can in some cases provide answers to the issues of affordable housing by allowing for the reuse of existing state houses on new sites, with minor adaptations to the interior. Thereby keeping it an economically viable adaptation measure, especially since 
the older New Zealand houses are produced by durable but rare timbers.

The flexibility and the mobility of the New Zealand home does come at a cost since the light and modular construction needs to remain simple to stay flexible and mobile. This could be counteracted by the pressing need of improving the indoor environmental standards of New Zealand homes, the country already creating better standards for the building envelope.

The earthquake prone country is unlikely to leave the strong timber framed constructions behind as their primary means of construction. However, to realize the adaptive potential the building designs need to accommodate flexibility while securing a better envelope [16].

\section{Discussion}

Adaptation to climate change in oceanic climates are in literature often described as a problem either with flooding or with overheating. Rarely are holistic solutions discussed, even though the practitioners will have to solve every issue they are faced with, some have immediate and sudden effect like coastal and flashfloods, but the issues transcend any single solution, and the problem must be solved as a whole.

The economic and cultural bearing in adaptation of residential architecture to climate change are likewise an important aspect. Because smaller residential developments and single-family houses tend to be more economically constrained than larger residential and commercial developments. Therefore, understanding how existing construction methods in the common residential architecture work in relation to climate change scenarios, can prove helpful in determining the local adaptations.

The naturally developed building methods in the individual countries might provide a realistic framework for other countries future adaptations in related landscapes and climate.

However, there is need for an effort to translate the strategies into local building cultures. The heavy Danish constructions as is the current standard may have either to be supplanted by lighter construction methods or develop a heavy construction equivalent to flexible New Zealand house. By creating concrete or masonry elements that can be dismantled or expanded upon easily, although it will never become as "do it yourself" as a lighter construction, it could provide a much larger degree of flexibility and mobility for the buildings, compared to the relatively locked houses in most Danish architecture today. Utilizing a disposable lower floor like in Dutch housing, could help solve flooding issues although it could a have a large impact on the way we need to inhabit our buildings in the future, it need to be followed with a certain set of social practice [4],[5],[9],[34]. New Zealand architecture need to create better envelopes and regionalize the standard houses to the different climates. It is important for the New Zealand house to maintain its strengths in flexibility and mobility while the existing and future building stock is improved in the building envelope. There needs to remain a low interconnectivity in building layers to keep the structure simple.

Understanding how building professionals conceptualize buildings in the context of landscape and climate could become an important factor for implementing adaptations in regard to future changes in climate since the natural world we inhabit shapes our approach to how we shape it [35]. The new adaptive measures should therefore match the building culture, but contribute solid new methods for adaptation to climate change.

\section{Conclusion}

The potential adaptation to climate change in oceanic residential architecture might be found in the bioclimatic designs features of the regions, since it is already part of the local building culture, and requires little behavioral attunement for the inhabitants of the buildings. One of the main problem with adapting to climate change in residential architecture is economy; hence picking the low hanging fruits presented in predictive bioclimatic designs, instead of complex or technological solutions, could be feasible.

Architects and designers in cold climates like the Danish might have to look at warmer climates for solutions, like integrated shutters and thermal mass, trombe walls, etc., in order to adapt to future temperatures without maladaptation of low energy architecture. However, the local building culture will persist. Therefore, understanding the vulnerabilities of the existing residential architecture, and how to mitigate these are important.

Danish architecture might benefit from a more flexible approach akin to New Zealand's housing. While harder to implement in heavy constructions, it could prove to be valuable not just from an adaptive perspective but as an implementation of circular economy in the building mass as well. The materials would essentially be banked when part of the construction and returned to circulation at disassembly. Flexibility of modification is easier in the lighter timber constructions that have become prevalent in the Danish building industry along with the developments of sustainability in Danish architecture. The use of lighter constructions could also lower the embedded energy of Danish housing, without sacrificing energy efficiency.

Essentially Danish architecture might benefit from lighter constructions and if the focus shift towards sustainable wooden constructions that have the added benefit of lowering the embedded energy of the materials. Which could become a primary factor for mitigating green house gasses in future Danish building design. 
Flexibility in housing constructions could prove to be effective against several effects of climate change if implemented right. Although issues with landownership could cause problems for retreat strategies, that require the movement of the entire building as seen in New Zealand.

The reactive and defensive designs of Dutch housing architecture might also see some use in Danish housing, but amphibious housing might be overcomplicating the design of low residential architecture that is not in an immediate flood zone. Best practice would be not to build in flood prone areas if there are alternatives, which there is in countries with lower population densities than in the Netherlands.

Both Denmark and Holland could learn from the focus on environmental and ecological footprint of the New Zealand houses, and a less narrow focus on energy savings. The strict energy regulations have created buildings that just barely reach the minimum requirements for indoor environments, and reducing the $\mathrm{CO} 2$ emissions from materials and constructions. Thereby creating houses that may be more flexible in handling the coming changes to the weather and climate.

The comparison does show that certain strategies develop as a response to the environmental circumstances. Further investigation must be made into the preconceptions and experiences of the building professionals in Denmark, to understand how the different adaptations could be implemented in the design of the Danish residence to respond to climate change. Understanding how these different strategies could fit in the cultural context could be validated through simulations of exemplary architectural designs. To understand the ingrained culture in the buildings praxis and the social practices of inhabitant of the cultures [36], interviews with building professionals could provide a level of experience and understanding to the coming experimental stages of the research.

\section{References}

1. IPCC. Climate Change 2014: Synthesis Report. Contribution of Working Groups I, II and III to the Fifth Assessment Report of the Intergovernmental Panel on Climate Change. (IPCC, 2014).

2. IPCC. Global Warming of $1.5^{\circ} \mathrm{C}$. Summary for Policymakers. (2018).

3. Kottek, M., Grieser, J., Beck, C., Rudolf, B. \& Rubel, F. Meteorol. Zeitschrift 15, 259-263 (2006).

4. Kunreuther, H. \& Weber, E. U. J. Consum. Policy 37, 397-411 (2014).

5. Fyhn, H. \& Baron, N. Soc. Nat. Resour. 30, 514555 (2017).

6. Roders, M. \& Straub, A. Build. Environ. 83,
168-176 (2015).

7. Groat, L. N. \& Wang, D. Architectural Research Methods. (Wiley, 2013).

8. Lind, O., Møller, J. \& Dirckinck-Holmfeld, K. Bag Hokken: Det Danske Parcelhus i Lyst Og Nød. (Arkitektens Forlag, 1996).

9. Watson, D. \& Adams, M. C. Design for Flooding. (Wiley, 2011).

10. Bygningsreglementet. 2017, (2017).

11. Lauring, M. Bolig Og Bebyggelse i Boredygtigt Perspektiv. (Arkitektskolen i Aarhus, 1998).

12. Fritzbøger, B. Kulturskoven : Dansk Skovbrug Fra Oldtid Til Nutid. (DSR Forlag, 2005).

13. Klunder, G. Sustainable Solutions for Dutch Housing : Reducing the Environmental Impacts of New and Existing Houses. (Delft : Delft University Press, 2005).

14. Rasmussen, S. E. Byer Og Bygninger. Bind 2. (Fonden til Udgivelse af Arkitekturværker, 1992).

15. Park, G. N. Ngā Uruora: The Groves of Life. Ecology and History in a New Zealand Landscape. (Victoria University Press, 1995).

16. White, V., Jones, M., Cowan, V. \& Chun, S. BRANZ 2015 House Condition Survey Condition Comparison by Tenure. (2017).

17. BRANZ. Renovate: Villa. Available at: https://www.renovate.org.nz/villa. (Accessed: 15th May 2018)

18. Sustainia \& Realdania. KLIMA100. (2018).

19. Lolland Kommune. (2016).

20. Sjöman, J. D. \& Gill, S. E. Urban For. Urban Green. 13, 304-314 (2014).

21. van der Nat, A., Vellinga, P., Leemans, R. \& van Slobbe, E. Ecol. Eng. 87, 80-90 (2016).

22. Marsh, R. J. Archit. 22, 225 (2017).

23. English, E., Klink, N. \& Turner, S. E3S Web Conf. 7, 13009 (2016).

24. Hamdy, M. H. M., Carlucci, S., Hoes, P. P.-J. J. P.-J. \& Hensen, J. L. M. M. J. Build. Environ. Build. Environ. Build. Environ. 122, 307 (2017).

25. Filippidou, F., Nieboer, N. \& Visscher, H. Energy Build. 132, 107-116 (2016).

26. Ministry for the Environment. Environment New Zealand 2007 - Summary. (2007).

27. Bernhardt, J. A Deeper Shade of Green: Sustainable Urban Development, Building and 
Architecture in New Zealand. (Balasoglou Books, 2008).

28. Hansen, E. K., Olesen, G. G. H. \& Mullins, M. Proc. IEEE 101, 2436-2449 (2013).

29. Buchin, O., Hoelscher, M.-T., Meier, F., Nehls, T. \& Ziegler, F. Energy Build. 114, 27-37 (2016).

30. Palmer, J. S. et al. in 7th Australasian Housing Researchers' Conference, 6- 8th February 2013 Esplanade Hotel, Fremantle, Western Australia (Curtin University, 2013).

31. Murgul, V. et al. Procedia Eng. 165, 869-875 (2016).

32. Ibelings, H. in (Rotterdam : Netherlands Architecture Institute, 2004).

33. Gul, M. S. \& Menzies, G. F. Energy Policy 45, 752-761 (2012).

34. Shove, E. Theory, Cult. Soc. 27, 277-288 (2010).

35. Ingold, T. J. R. Anthropol. Inst. 13, S38 (2007).

36. Shove, E., Trentmann, F. \& Wilk, R. Time, Consumption and Everyday Life : Practice, Materiality and Culture. (Oxford : Berg Publishers, 2009). 